\title{
KAJIAN SEMIOTIKA PADA PAPAN REKLAME KAMPANYE PEMILIHAN CALON GUBERNUR DAN WAKIL GUBERNUR JAWA BARAT 2018-2023
}

\author{
Dewi Indah Susanti \\ Universitas Indraprasta PGRI \\ dewimughni@gmail.com
}

\begin{abstract}
Abstrak
Tulisan ini bertujuan untuk mengetahui deskripsi penanda (signifier) dan petanda (signified) serta makna denotasi dan konotasi yang terkandung dari papan reklame kampanye calon gubernur dan wakil gubernur Jawa Barat 20182023. Metode pengumpulan data dalam artikel ini adalah metode dokumentasi dan metode analisis data yang digunakan dalam artikel ini adalah metode analisis semiotika. Analisis semiotika dengan berlandaskan pada teori Roland Barthes, yaitu pemaknaan pada penanda, petanda, denotasi, dan konotasi. Hasil penelitian menunjukkan bahwa dengan menggunakan semiologi Roland Barthes pada papan reklame kampanye politik ini, ditemukan adanya hubungan antara penanda (signifier) dan petanda (signified) di dalam sebuah tanda sehingga menjelaskan secara nyata sebuah tataran denotatif. Kemudian terdapat pula interaksi antara tanda dengan perasaan atau emosi pembaca serta nilai-nilai kebudayaan di dalam papan reklame, sehingga membawa kepada tataran konotasi yang memberikan makna tersendiri dan memiliki pengaruh kepada kerangka berpikir dari pembaca.
\end{abstract}

Kata kunci : semiotika, penanda, petanda, denotasi, dan konotasi

\begin{abstract}
This paper aims to determine the signifier description and signified as well as the meaning of denotation and connotation contained in the campaign billboard for West Java 2018-2022 gubernatorial and vice governor candidates. The data collection method in this article is the documentation method and the data analysis method used in this article is the semiotic analysis method. Semiotic analysis is based on Roland Barthes's theory, which is the meaning of signifier, signified, denotations, and connotations. The results showed that by using Roland Barthes's semiology on this political campaign billboard, there was a relationship between the signifier and the signified in a sign so as to clearly explain a denotative level. Then there is also the interaction between the sign with the feeling or emotion of the reader and cultural values on the billboard, so that it brings to the level of connotation that gives its own meaning and has an influence on the frame of mind of the reader.
\end{abstract}

Keyword: Language, Language Style, Debate

\section{PENDAHULUAN}

Panggung politik Indonesia tengah diramaikan perebutan kursi kekuasaan di daerah. Pemilihan kepala daerah (pilkada) serentak di 171 daerah tahun ini menyedot perhatian publik. Partai politik saling tarik-menarik dukungan terhadap para bakal calon. Demi meraih kemenangan, mereka berlomba meng-usung calon terbaiknya.

Selain persaingan antar parpol, para pasangan calon pun terlibat dalam kompetisi menarik atensi publik. Salah satu cara mereka adalah membuat singkatan nama dan papan reklame 
kampanye yang unik. Selain untuk memikat perhatian khalayak umum, singkatan dan papan reklame kampanye yang unik juga untuk memberi kesan dan mudah diingat oleh pemilih.

Pilgub Jawa Barat tahun 2018 menarik perhatian serius dari partai-partai politik besar karena besarnya jumlah pemilih, yaitu jumlah DPT-nya ada 32.809.057 (70,6 \% dari total penduduk Jabar). Pilgub di tanah Priangan ini dapat dikatakan menjadi pertaruhan antara parpol papan atas (PDIP, Golkar, Gerindra, dan Demokrat) dan parpol papan tengah (PKB, PKS, dan PAN). Partai-partai ini memiliki keyakinan bahwa pemenang di pilkada Jabar ini akan menang juga pada pileg dan pilpres 2019 nanti.

Terpilihlah empat pasang cagub dan cawagub Jawa Barat yang secara resmi telah mendaftar ke KPUD Jawa Barat, Rabu 10 Januari 2018. Mereka adalah pasangan SudrajatAhmad Syaikhu (PKS, Gerindra dan PAN); Deddy Mizwar-Dedi Mulyadi (Partai Demokrat dan Golkar); Ridwan Kamil-Uu Ruzhanul Ulum (PPP, PKB, Nasdem dan Hanura); dan TB Hasanudin-Anton Charliyan (PDIP).

Pilgub Jabar diikuti oleh empat kandidat, keempatnya memuat spanduk dan slogan kampanye yan semenarik mungkin untuk memikat para pemilih. Spanduk kampanye tersebut pastilah mempunyai makna yang tersembunyi, lewat hubungan antara tanda (Sign), penanda (Signifier), dan petanda (Signified) akan menuntun kita ke arah makna yang tersembunyi dari spanduk kampanye tersebut. Setiap tanda selalu memperoleh pemaknaan awal yang dikenal secara umum (denotasi) dan oleh Barthes disebut sistem primer, sedangkan segi pengembangannya disebut sistem sekunder.

Roland Barthes (dalam Sobur, 2004:63) seorang tokoh pemikir strukturalis dan juga seorang tokoh dalam semiotik yang telah cukup banyak memberikan kontribusinya dalam pengembangan semiotik khususnya strukturalis. Barthes adalah penerus Saussure yang mengembangkan teori penanda (signifier) dan petanda (signified) menjadi lebih dinamis. Oleh karena itu, penulis merasa perlu untuk melakukan kajian mengenai semiotika pada spanduk kampanye pilgub Jabar 2018-2023.

Penelitian ini sejalan dengan penelitian yang dilakukan oleh Alfian (2015) dalam skripsinya yang berjudul Änalisis Semiotika Papan Reklame Kampanye Politik Calon Legislatif DPRD Tahun 2014 Dapil 1 (Tanate Riattang Barat, Tanate Riattang Timur, dan Palakka) di Kabupaten Bone. Hasil penelitian tersebut menemukan makna semiotika berupa gambaran kepribadian, aktivitas, prinsip, serta tujuan caleg yang memiliki persamaan dan perbedaan makna signifikan di beberapa bagian objek yang menjadi bahan penelitian.

Sama halnya dengan Alfian, Indra Saputra (2012) juga menganalisis Semiotika Wacana Iklan Rokok A Mild edisi Go Head versi Gapai Mimpi Go Ahead, Setia Kawan Go Ahead, dan Pikir Pendek Go Ahead. Analisis semiotika tersebut juga mengacu pada toeri Roland Barthes. Oleh karena itu, penulis merasa perlu untuk melakukan kajian mengenai semiotika pada papan reklame kampanye pilgub Jabar 2018-2023 dengan meng-gunakan teori Barthes.

\section{METODE PENELITIAN}

Metode penelitian dalam penelitian ini adalah penelitian kualitatif deskriptif. Subjek dalam penelitian ini adalah calon gubernur dan wakil gubernur Jawa Barat 2018-2023.

Instrumen yang digunakan antara lain: dokumentasi, catatan, dan sebagai-nya. Peneliti berkedudukan sebagai instrumen utama dalam pengumpulan data. Instrumen yang digunakan sangat menentukan kelancaran proses pengumpulan data dan analisis hasil penelitian itu sendiri.

Penelitian dengan menggunakan analisis semiotika merupakan teknik penelitian bagi kajian komunikasi yang cenderung lebih banyak mengarah pada sumber maupun penerimaan 
pesan. Aspek yang diteliti dalam papan reklame kampanye politik dari calon gubernur dan wakil gubernur ini akan menggunakan pendekatan kerangka analisis Roland Barthes, signifikasi yaitu penanda, petanda, denotasi dan konotasi.

\section{HASIL DAN PEMBAHASAN}

Deskripsi data dimaksudkan untuk memberikan gambaran tentang data yang diteliti. Data yang diteliti adalah papan reklame empat kandidat pasangan Pilgub Jabar 2018-2023.

Papan Reklame Kandidat Nomor Urut 1 Pilgub Jabar 2018-2023

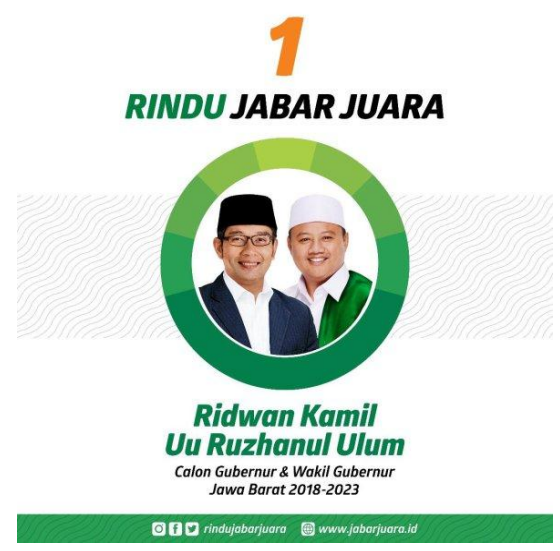

Tabel 1.Deskripsi Penanda (Signifier) Petanda (Signified) kandidat Nomor Urut 1 Pilgub Jabar 2018-2023

\begin{tabular}{|c|c|}
\hline Penanda (signifier) & Petanda (Signified) \\
\hline Angka 1 & \multirow{4}{*}{$\begin{array}{l}\text { Papan reklame ini dibuat untuk menginformasikan } \\
\text { dan memengaruhi para pemilih Pilgub Jabar untuk } \\
\text { memilih nomor urut } 1 \text { (Ridwan-Uu). }\end{array}$} \\
\hline Lingkaran berwarna hijau & \\
\hline Jargon tulisan Rindu Jabar Juara & \\
\hline Tulisan Rindu menggunakan warna 1 & \\
\hline
\end{tabular}

Tataran Denotatif Pasangan Nomor Urut 1 (Ridwan Kamil-Uu)

Pada papan reklame ini terpampang jelas foto kedua pasangan kandidat, dua sosok pria dewasa dan menggunakan peci. Ridwan Kamil mengenakan jas biru dan peci hitam, sedangkan Uu Ruzhanul mengenakan kemeja putiih, sorban hijau, dan peci putih. Forto kedua pasangan dilingkari dengan warna hijau,

Angka 1 menunjukkan kedua kandidat merupakan pasangan nomor urut 1. Di bawahnya tertulis juga jargon pasangan yaitu "Rindu Jabar Juara".

Setelah tertulis nama kedua pasangan kandidat, kemudian di bawahnya dituliskan Calon Gubernur dan Wakil Gubernur Jawa Barat 2018-2023.

Tataran Konotatif Pasangan Nomor Urut 1 (Ridwan Kamil-Uu)

Pada papan reklame ini menunjuk-kan kedua pasangan yang menunjukkan ekspresi tersenyum. Kedua pasangan mengenakan pakaian jas dan peci, hal itu dimungkinkan untuk menunjukkan bahwa kedua pasangan religius. Hal ini dilakukan untuk dapat menarik hati pemilih dari kaum muslim dan menunjuk-kan walaupun mereka diusung dari partai nasional dan agama, namun mereka tetap sosok religius.

Tulisan jargon Rindu Jabar Juara, dengan menegaskan kata Rindu meng-gunakan warna hijau menunjukkan bahwa tulisan itu mempertegas bahwa kata Rindu di sini salah satunya merupa-kan singkatan dari nama Ridwan Kamil dan UU Ruzhanul Ulum. 
Jargon Rindu Jabar Juara, dapat juga dimaksudkan bahwa kalimat ter-sebut merupakan kesan yang ingin disampaikan kepada warga Jabar sebagai pemilih bahwa dengan memilih pasangan Rindu (Ridwan-UU) maka Jabar akan menjadi juara.

Gambar 2 Gambar Papan Reklame Kandidat Nomor Urut 2 Pilgub Jabar 2018-2023

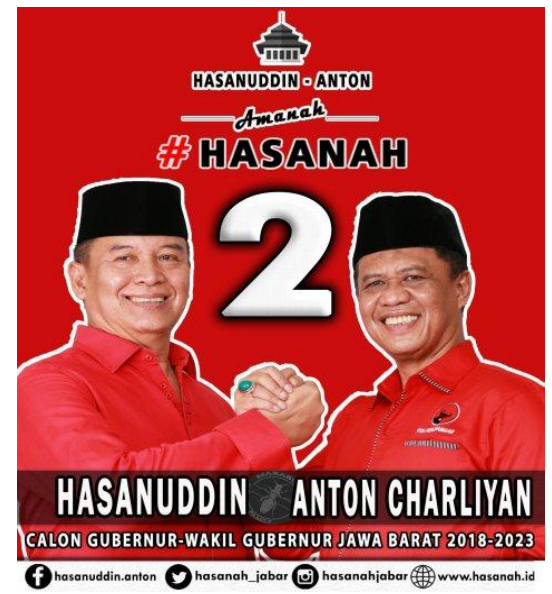

Tabel 2.Deskripsi Penanda (Signifier) Petanda (Signified) kandidat Nomor Urut 2 Pilgub Jabar 2018-2023

\begin{tabular}{|c|c|}
\hline Penanda (Signifier) & Petanda (Signified) \\
\hline Gedung Sate & \multirow{7}{*}{$\begin{array}{l}\text { Papan reklame ini dibuat untuk } \\
\text { menginformasikan dan } \\
\text { memengaruhi para pemilih Pilgub } \\
\text { Jabar untuk memilih nomor urut } 2 \\
\text { (Hasanudin dan Anton Charliyan). }\end{array}$} \\
\hline Tulisan amanah & \\
\hline Tulisan \# hasanah & \\
\hline Angka 2 & \\
\hline Kedua kandidat mengenakan kemaja merah & \\
\hline Nama kedua pasangan (Hasanudin dan Anton Charliyan) & \\
\hline $\begin{array}{l}\text { Tulisan Calon Gubernur dan Wakil Gubernur Jawa Barat } \\
\text { 2018-2023 }\end{array}$ & \\
\hline
\end{tabular}

Tataran Denotatif Pasangan Nomor Urut 2 (Hasanudin-Anton Charliyan)

Pada papan reklame ini ter-pampang jelas foto kedua pasangan kandidat, dua sosok pria dewasa dan menggunakan peci. Keduanya meng-gunakan kemeja merah berlambang banteng di bagian dada sebelah kiri yang menunjukkan bahwa keduanya diusung dari Partai Demokrasi Indonesia Perjuangan (PDIP).

Pada bagian atas papan reklame, terdapat gambar gedung sate, hal tersebut menjelaskan bahwa gedung tersebut adalah gedung Pemerintah Provinsi Jawa Barat.

Terdapat tulisan Amanah dan \# Hasanah. Angka 2 menunjukkan kedua kandidat merupakan pasangan nomor urut 2. Setelah tertulis nama kedua pasangan kandidat yaitu, Hasanudin dan Anton Charliyan, kemudian di bawahnya dituliskan Calon Gubernur dan Wakil Gubernur Jawa Barat 2018-2023.

Tataran Konotatif Pasangan Nomor Urut 2 (Hasanudin-Anton Charliyan)

Pada papan reklame ini terdapat gambar gedung Sate, hal ini ingin menginformasikan bahwa kedua pasangan tersebut merupakan calon Gubernur dan Wakil Gubernur Jawa Barat. Hal tersebut dikarenakan, Gedung Sate merupakan salah satu ikon Provinsi Jawa Barat (gedung pemerintahan Pemprov Jabar).

Terdapat tulisan Amanah dan Jargon \# Hasanah. Hal tersebut memberikan kesan bahwa Hasanudin dan Anton Charliyan adalah orang yang amanah. Kata Hasanah, merupakan singkatan dari Hasanudin dan Anton Charliyan, orang yang amanah. 
Latar belakang merah pada papan reklame dan kemeja merah yang yang kedua kandidat, ingin mempertegas bahwa keduanya adalah kandidat dari Partai Demokrasi Indonesia Perjuangan (PDIP) satu-satunya paratai pengusung kedua kandidat tersebut.

\section{Gambar 3 Gambar Papan Reklame Kandidat Nomor Urut 3 Pilgub Jabar 2018-2023}

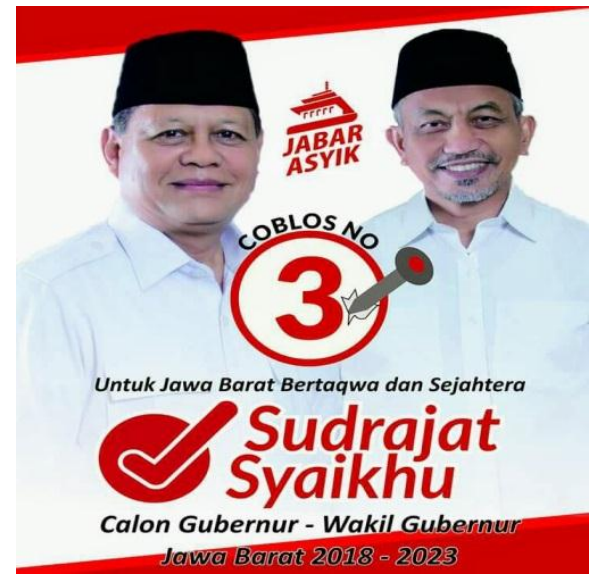

Tabel 3.Deskripsi Penanda (Signifier) Petanda (Signified) kandidat Nomor Urut 3 Pilgub Jabar 2018-2023

\begin{tabular}{|c|c|}
\hline Penanda (Signifier) & Petanda (Signified) \\
\hline Lambang logo gedung Sate & \multirow{6}{*}{$\begin{array}{l}\text { Papan reklame ini dibuat } \\
\text { untuk menginformasikan } \\
\text { dan memengaruhi para } \\
\text { pemilih Pilgub Jabar untuk } \\
\text { memilih nomor urut } \\
\text { 3(Sudrajat dan Syaikhu). }\end{array}$} \\
\hline Tulisan Jabar Asyik & \\
\hline Tulisan coblos nomor 3 dan gambar paku & \\
\hline Tanda Centang & \\
\hline Tulisan untuk Jawa Barat bertaqwa dan sejahtera & \\
\hline Sudrajat-Syaikhu calon Gubernur da Wakil Gubernur Jawa Barat & \\
\hline Kedua kandidat memakai kemeja dan peci putih & \\
\hline
\end{tabular}

Tataran Denotatif Pasangan Nomor Urut 3 (Sudrajat-Syaikhu)

Pada papan reklame di atas terdapat gambar gedung sate, menunjuk-kan ikon Jawa Barat. Terdapat tulisan Jabar Asyik.

Terdapat tulisan coblos nomor 3 yang dilingkari dan kemudian nomor tersebut dicoblos menggunakan gambar paku.

Terdapat tulisan slogan "Untuk Jawa Barat Bertaqwa dan Sejahtera" untuk menginformasikan kepada para pemilih.

Terdapat tanda centang di sebelah tulisah Sudrajat-Syaikhu sebagai calon Gubernur dan Wakil Gubernur Jawa Barat 2018-2023.

Tataran Konotatif Pasangan Nomor Urut 3 (Sudrajat-Syaikhu)

Pada papan reklame di atas terdapat ikon gedung Sate, hal ini inngin meng-informasikan bahwa kedua pasangan tersebut merupakan calon Gubernur dan Wakil Gubernur Jawa Barat. Hal tersebut dikarenakan, Gedung Sate merupakan salah satu ikon Provinsi Jawa Barat (gedung pemerintahan Pemprov Jabar).

Terdapat tulisan jargon "Jabar Asyik". Hal ini dimaksudkan ingin memberikan kesan dan ingin mengambil suara dari para pemilih muda, dengan mencantumkan kata "Asyik" yang terdengar lebih santai dan diterima semua kalangan. Kata "Asyik" juga merupakan singkatan dari nama kedua kandidat (Ahmad Sudrajat dan Syaikhu).

Gambar paku dan nomor yang dicoblos merupakan wujud atau bentuk informasi kepada para pemilih agar dapat mecoblos nomor urut 3. 
Kedua kandidat menggunakan peci dan kemeja putih, serta latar belakang papan reklame putih, untuk memberikan kesan bahwa kedua kandidat adalah orang yang bersih dari hal-hal yang negatif.

Warna merah pada tulisan "Jabar Asyik", angka 3, tanda centang dan nama kedua kandidat dapat memberi kesan bahwa papan reklame tersebut ingin memberikan penegasan pada tulisan tersebut (dimasudkan agar pemilih ingat dan memilih mereka).

Gambar 4 Gambar Papan Reklame Kandidat Nomor Urut 4 Pilgub Jabar 2018-2023

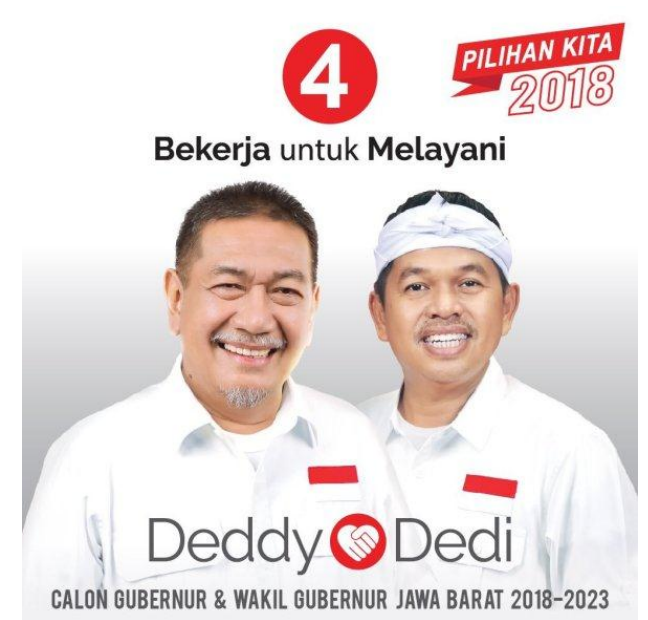

Tabel 3.Deskripsi Penanda (Signifier) Petanda (Signified) kandidat Nomor Urut 3 Pilgub Jabar 2018-2023

\begin{tabular}{|c|c|}
\hline Penanda (Signifier) & Petanda (Signified) \\
\hline Angka 4 berwarna merah & \multirow{7}{*}{$\begin{array}{l}\text { Papan reklame ini dibuat } \\
\text { untuk menginformasikan } \\
\text { dan memengaruhi para } \\
\text { pemilih Pilgub Jabar } \\
\text { untuk memilih nomor } \\
\text { urut 4(Deddy Mizwar } \\
\text { dan Dedi Mulyadi). }\end{array}$} \\
\hline Tulisan "Pilihan Kita 2018" & \\
\hline Slogan "Bekerja untuk Melayani" & \\
\hline $\begin{array}{l}\text { Kedua kandidat mengenakan baju kemeja putih lengan pendek dan di saku } \\
\text { kemejanya terdapat lambang bendera merah putih }\end{array}$ & \\
\hline Ada lambang jabat tangan & \\
\hline Dedi Mulyadi mengenakan kain ikat di kepala berwarna putih & \\
\hline Tulisan calon Gubernur dan Wakil Gubernur Jawa Barat 20 & \\
\hline
\end{tabular}

Tataran Denotatif Pasangan Nomor Urut 4 (Deddy Mizwar-Dedi Mulyadi)

Pada papan reklame di atas, terdapat angka 4, menunjukkan nomor urut kedua pasangan. Di sebelah kanan atas terdapat tulisan "Pilihan Kita 2018". Slogan kampanye pasangan duo DM ini yaitu "Bekerja untuk Melayani".

Terdapat logo kedua tangan yang sedang saling berjabat, di antara dua nama kandidat pasangan calon. Ada lambang bendera merah putih di kemeja kedua kandidat.

Tataran Konotatif Pasangan Nomor Urut 4 (Deddy Mizwar-Dedi Mulyadi)

Pada papan reklame di atas, terdapat tulisan "Pilihan Kita 2018", hal ini dimaksudkan untuk memberikan informasi dan mengajak para pemilih di Jawa Barat untuk memilih Deddy Mizwar dan Dedi Mulyadi.

Terdapat tulisan nomor 4 yang merupakan nomor urut kedua kandidat.

Terdapat tulisan slogan "Bekerja untuk Melayani" diartikan untuk mem-beri informasi dan kesan bahwa jika kandidat terpilih, mereka akan bekerja untuk melayani warga Jawa Barat. 
Kedua pasangan mengenakan kemeja berwarna putih. Hal tersebut dapat memberikan kesan bahwa kedua-nya adalah orang yang bersih dari KKN. Di saku kemeja keduanya terdapat lambang bendera merah putih, menunjuk-kan keduanya bersifat nasionalis.

Terdapat logo tangan yang sedang saling berjabat, dapat memberikan kesan bahwa keduanya akan saling bekerjasama dan bersatu membangun Jawa Barat.

Dedi Mulyadi mengenakan ikat kepala untuk memberik kesan bahwa ia mencintai adat budaya Jawa Barat.

\section{SIMPULAN}

Pada media luar ruang khususnya papan reklame kampanye politik calon Gubernur dan Wakil Gubernur Jawa Barat 2018, ditemukan makna Semiotika yang ditentukan oleh tampilan gambar dan sistem tanda dan terdapat pemaknaan yang ditemukan pada semua papan iklan reklame kampanye politik tersebut.

Dengan menggunakan semiologi Barthes pada papan reklame kampanye politik ini, ditemukan adanya hubungan antara penanda (signifier) dan petanda (signified) di dalam sebuah tanda, sehingga menjelaskan secara nyata sebuah tataran denotatif. Kemudian terdapat pula interaksi antara tanda dengan perasaan atau emosi pembaca serta nilai-nilai kebudayaan di dalam papan reklame, sehingga membawa kepada tataran konotasi yang memberikan makna tersendiri dan memiliki pengaruh kepada kerangka berpikir dari pembaca.

Dengan adanya papan reklame politik di media luar ruang, diharapkan para kandidat yang akan mengikuti kontestasi politik dapat menyampaikan pesan yang komunikatif dan membangun untuk arah yang lebih baik. Untuk para pemilih, diharapkan dapat lebih kritis dan dapat memaknai pesan yang disampaikan oleh media luar ruang dengan baik.

\section{DAFTAR PUSTAKA}

Barthes, R. (2007). Petualangan Semiologi. Yogyakarta : Pustaka Pelajar.

Bungin, B. (2007). Metode Penelitian Kualitatif. Jakarta: PT Raja Grafindo Persada.

Chaer, A. (2002). Pengantar Semantik Bahasa Indonesia. Jakarta : Rineka Cipta.

Finoza, L. (2008). Komposisi Bahasa Indonesia. Jakarta: diksi Insan Mulia.

Keraf, G. (2002). Diksi dan Gaya Bahasa. Jakarta: Gramedia Pustaka Utama.

Sobur, A. (2004). Semiotika Komunikasi. Bandung : Remaja Rosdakarya.

Artikel:

Alfian. (2015). “Änalisis Semiotika Papan Reklame Kampanye Politik Calon Legislatif DPRD Tahun 2014 Dapil 1 (Tanete Riattang Barat, Tanete Riattang, Tanete Riattang Timur, dan Palakka di Kabupaten Bone”. Makasar: UIN Alauddin Makassar.

Saputra, I. (2012). "Analisis Semiotik Wacana Ilkan Rokok A Mild Edisi Go Ahead Versi Gapai Mimpi, A head Setia da Pikir Pendek Go Ahead". (http://indrasaputra999.blogspot.com/2012/10/analisis-semiotik-wacana-iklanrokok_12.html). 